RESEARCH ARTICLE

\title{
Investigation of Antituberculosis from Medicinal Plant of Community Ethnic in South Sulawesi
}

\author{
Herlina Rante ${ }^{1, *}$, Gemini Alam ${ }^{2}$, Sartini $^{1}$, Andi Dian Permana ${ }^{1}$, Usmar $^{3}$, Rahmita Burhamzah ${ }^{4}$, \\ Alimuddin Ali $^{5}$ and Mery Budiarti ${ }^{6}$
}

\begin{abstract}
${ }^{1}$ Laboratory of Pharmaceutical Microbiology, Faculty of Pharmacy, University of Hasanuddin, Makassar, Indonesia, ${ }^{2}$ Laboratory of Pharmacognosy and Phytochemistry, Faculty of Pharmacy, University of Hasanuddin, Makassar, Indonesia, ${ }^{3}$ Laboratory of Biopharmacy, Faculty of Pharmacy, University of Hasanuddin, Indonesia, ${ }^{4}$ Laboratory of Pharmaceutical, Faculty of Pharmacy, University of Hasanuddin, Makassar, Indonesia, ${ }^{5}$ Faculty of Pharmacy, University of Hasanuddin, Makassar, Indonesia, ${ }^{6}$ Department of Biology, Faculty of Math and Science, Universitas Negeri Makassar, Makassar, Indonesia, ${ }^{7}$ Balai Besar Penelitian dan Pengembangan Tanaman Obat dan Obat Tradisional, Makassar, Indonesia
\end{abstract}

A R T I C L E H I S T O R Y

Received: July 23, 2019

Revised: November 21, 2019

Accepted: November 28, 2019

DOI

$10.2174 / 1871526520666191216121302$
Abstract: Background: Tuberculosis is one of the transmitted diseases that has been claimed as one of the most serious health problems worldwide resulting in death, as reported in WHO in Global Tuberculosis Report 2014. It has been predicted that 9 million people suffer from tuberculosis disease and 1.5 - 2 million deaths occur by this disease.

Objective: The aim of this research is to know the species of plant used as anti-hematemesis medicine that has the activity of antituberculosis and antituberculosis-MDR and then investigate the phytochemistry characteristics of the compound from every parts of the plant extract that show the activity of antituberculosis and antituberculosis-MDR which is indicated by the value of Minimum Inhibitory Concentration (MIC) of the extracts.

Method: The extraction method used in this research was the maceration method. The antituberculosis activity test was investigated using MODS and LJ media methods. The isolation of the active compound was carried out using Bioassay Guided Fractionation and then the compound characteristics were identified using spectroscopy data.

Results: The results showed that extracts from Talas (Collocasia esculenta tuber) and Kariango (Acorus calamus rhizome) plants were active against M. tuberculosis. The FTIR spectroscopy data showed that three isolates obtained from Talas plants contained aliphatic $\mathrm{OH}$ and $\mathrm{C}-\mathrm{O}$ and $\mathrm{CH}$ groups. The MIC values of kariango and Talas extracts using the MODS method were $45 \mathrm{mg} / \mathrm{ml}$ and $40 \mathrm{mg} / \mathrm{ml}$, respectively.

Conclusion: Talas (Collocasia esculenta) tuber and Kariango rhizome ethanolic extract have a potency for antituberculosis and anti-MDR tuberculosis drugs.

Keywords: Anti Mybobacterium tuberculosis H37RV and MDR, ethanol extract, MODS, LJ.

\section{INTRODUCTION}

Tuberculosis is one of the transmitted diseases that has been claimed as one of the most serious health problems worldwide according to the WHO report in Global Tuberculosis Report 2014. It has been predicted that almost 9 million people suffer from tuberculosis and almost 1.5 to 2 million deaths occur because of this disease every year [1].

Globally, there are 13.7 million prevalent cases of chronic tuberculosis and 1.8 million deaths, especially in

*Address correspondence to this author at the Laboratory of Pharmaceutical Microbiology, Faculty of Pharmacy, University of Hasanuddin, Makassar, Indonesia; E-mail: herlinarante@unhas.ac.id developing countries [2]. In Indonesia, new cases of tuberculosis in 2006 counted as much as 600000 people and most of them were in productive ages (15-55 years old). Deaths due to tuberculosis were counted as much as 300 people per day and 100.000 cases per year. Thus, it become a challenge for the related parties to strive for controlling this infectious disease. One of the important efforts to be made is the early detection of the disease in order to handle this infectious disease easily [3]. The main therapy for tuberculosis disease is the use of anti-Mycobacterium. Therapy using antibiotic require a long time (around 6 months); therefore, it can decrease the obedience of patients undergoing therapy. It may increased antibiotics resistances [4]. 
It has been observed in Indonesia that \pm 50 million people are infected with the resistant strain of $M$. tuberculosis towards at least one kind of antituberculosis drug. The resistance towards antituberculosis drugs such as Isoniazid, streptomycin, ethambutol and rifampicin is caused by several factors like undisciplined therapy, lack of obedience in therapy, and the use of the single drug only [5].

An alternative effort that can be made for the discovery and development of the new better drugs in tackling the drug resistance case is by exploring the medicinal plants. About 350 types of natural sources, mainly from plants, have been used for antituberculosis therapy $[6,7]$. The use of the medicinal plants has become a tradition in society in several countries, including Indonesia. The use of plants and animals as the raw material of drugs in Indonesia has been existed since a long time ago. The knowledge of local ethnomedicine and community-based medicinal plant in Indonesia has become local wisdom for each ethnic and medicinal plant diversity Especially in South Sulawesi.

There are 6 ethnics in South Sulawesi that have used 15 species of medicinal plants as antihematemesis drugs [8, 9]. Hematemesis is one of the symptoms of tuberculosis disease. Several medicinal plants that are used empirically in the therapy of hematemesis in South Sulawesi ethnic have been reported but have not investigated for their scientific aspect yet. Based on that data, this research will investigate as much as 10 species of anti-hematemesis medicinal plants for their antituberculosis effect.

\section{MATERIALS AND METHOD}

\subsection{Materials}

Materials that were used in this research are Ethanol 70 $\%$, TLC Plate, Silica gel, Ethyl acetate, Ethanol p.a, LJ Media, Middle brock Media, Isoniazid antibiotic, M. tuberculosis $\mathrm{H} 37 \mathrm{RV}$ and MDR Isolate, PANTA $^{\mathrm{TM}}$ - Antimicrobial agent mixture, Gliserol, OADC.

\subsection{Sample Extraction}

Sample plants that have been powdered (150 gram) were extracted using the maceration method which involves ethanol $70 \%$ as much as $1000 \mathrm{~mL}$ for 72 hours. After 72 hours, the filtrates were evaporated using a rotary evaporator. Evaporated extract then inserted to an oven at a temperature of $40^{\circ} \mathrm{C}$ until it becomes viscous extract. Unidentified samples were determined.

\subsection{Antituberculosis and Anti-MDR Tuberculosis Activ- ity Test}

The testing of antituberculosis and anti-MDR tuberculosis activity was carried out to all plant extracts. Mycobacterium tuberculosis Strain H37Rv and MDR-TB used were obtained from the Microbiology Laboratory of the Faculty of Medicine, Hasanuddin University. Strains were grown in the liquid media of Middlebrook 7H9 (Difco Laboratories) with the Oleat-Bovine Serum Albumin Dextrose Catalase (OADC) acid complex (Difco Laboratories) at $37^{\circ} \mathrm{C}$ which was agitated once daily for 2 weeks.
Testing for anti-TB activity and MDR-TB is done by referring to the MODS (Microscopic Observation Drug Susceptibility) method and Lowenstein Jensen medium [10]. A total of $50 \mu \mathrm{L}$ of the extracted sample was inserted into the well plate. Furthermore, MODS media is added as much as $940 \mu \mathrm{L}$. The culture of strain H37Rv and MDR in PBS solution to Standard No. $0.5 \mathrm{McF}$ arland $\left(1.5 \times 10^{8} \mathrm{cfu} / \mathrm{mL}\right)$ of 10 $\mu \mathrm{L}$ was inoculated into each well. As a positive control, Isoniazid (INH) was used with a final concentration of 1 ppm and positive control for MDR-TB was ofloxacin with a final concentration of $2 \mathrm{ppm}$. The plate was inserted into a plastic bag and incubated at $37^{\circ} \mathrm{C}$. Observations were made in the first and second weeks using an inverted high microscope.

The LJ medium (Lowenstein Jensen) is carried outby inserting the extracted sample into the $\mathrm{LJ}$ tube as much as 0.1 $\mathrm{mL}$ and then adding the LJ medium to reach a volume of 4 $\mathrm{mL}$. All test tubes are tightly closed and placed on the sloping position $30^{\circ}$ in the oven/inspisator which has been heated at $85^{\circ} \mathrm{C}$. It is then frozen/coagulated for 45 minutes, then removed and left at room temperature. All media tubes were inoculated as much as $10 \mu \mathrm{L}$ inoculums aseptically and then incubated at $37^{\circ} \mathrm{C}$ for 3 (three) weeks. Observations were carried out every week to monitor the presence and the growth of colonies.

\subsection{Determination of Minimum Inhibitory Concentra- tion (MIC)}

Extracts that showed high anti-TB and MDR activity were determined by MIC values. The extract was declared potential as anti-TB and MDR if it showed activity at concentrations of 100 to $500 \mathrm{ppm}$. Determination of MIC values was carried out by growing the culture of the strain H37RV and MDR-TB in the MODS and Lowenstein Jensen (LJ) medium in a concentration range of $1000 \mathrm{ppm}, 500 \mathrm{ppm}, 250$ ppm, $125 \mathrm{ppm}$ and $62.5 \mathrm{ppm}$. it was then incubated at $37^{\circ} \mathrm{C}$ for 3 weeks and was kept under observation. The MIC value is expressed as the smallest concentration of extract that does not show discoloration on the plate. Each extract was repeated with 3 replications.

\subsection{Phytochemistry Screening and Characterization of the Potential Extract}

Plant extracts that showed high activity (based on the MODS and MIC test) phytochemical screening was carried out. The extract was fractionated with Vacuum Column Chromatography with elution based on increased polarity gradients. Every faction combination is tested for TB activity and MDR-TB. The fraction that showed activity was carried out by isolation using Preparative Thin Layer Chromatography. The compounds obtained were characterized based on spectroscopic data.

\subsection{Fractionation Using Vacuum Liquid Chromatogra- phy Method}

To obtain the desired active compound, fractionation of ethanol extract was carried out which had anti TB activity and $2 \mathrm{~g}$ of MDR TB using Vacum Liquid Chromatography with multilevel mobile phase system. 
The stationary phase used was silica gel 60 for column chromatography (230-400 mesh) weighing $\pm 40 \mathrm{~g}$, and the mobile phase respectively was n-hexane, a mixture of $n$ hexane and ethyl acetate with a ratio of 9: $1(\mathrm{v} / \mathrm{v}), 8: 2(\mathrm{v} /$ $\mathrm{v}), 7: 3(\mathrm{v} / \mathrm{v})$ to $1: 1(\mathrm{v} / \mathrm{v})$, then ethyl acetate $100 \%$ and the last is $100 \%$ methanol. All mobile phases are $100 \mathrm{ml}$ each. The viscous ethanol extract was dissolved in methanol and then dried with silica gel 60 PF254. The mixture is placed into a sintered glass filter containing silica gel 60 for column chromatography and the top has been given filter paper that has the same diameter as the sintered glass filter. Furthermore, the mobile phase with increasing polarity gradients is constantly added and fractionation takes place with the help of a vacuum. The fraction obtained is then evaporated to dryness. The same profile of fraction in the thin layer chromatography are combined into one fraction. Each fractions was tested for anti-TB activity and MDRTB.

\subsection{Isolation Process Using Preparative TLC (Thin Layer Chromatography)}

Purification of the active fraction was carried out by preparative thin-layer chromatography. The stationary phase used was silica gel 60 PF254 with the n-hexane: ethyl acetate $(1: 7 \mathrm{v} / \mathrm{v})$ mobile phase. The sample, in this case, is the active fraction which is bottled elongated on the preparative silica gel $60 \mathrm{PF} 254$ plate (heated in a $110^{\circ} \mathrm{C}$ oven for 15 minutes). Then the band patches were appeared, marked and scraped. The resulting crust is dissolved in methanol with magnetic stirring. The solution was filtered using sintered glass filters with the help of a vacuum to separate isolates from silica gel 60 PF254. The solution was evaporated to dryness, then tested for anti-TB activity and MDR-TB.

\subsection{Purity Test of Active Isolates}

The purity test of active isolates used TLC with various mobile phases, the stationary phase of silica gel 60 PF254.

\subsection{Characterization of Active Isolates}

The characterization of active compounds was carried out using UV-Vis and infrared (IR) spectrophotometry. For IR Method, a small amount of active isolates is crushed together in $\mathrm{KBr}$ powder until it mixes perfectly and is printed with thin to pellet-shaped discs. This pellet is then analyzed by infrared spectra.

\subsection{Data Analysis}

The results of the measurements of an active compound activity in vitro and qualitative analysis of the character of the active compound were analyzed descriptively.

\section{RESULTS AND DISCUSSION}

In this research, ten species of plant medicine are used as anti-hematemesis in South Sulawesi society ethnic. Those are Collocasia esculenta tuber, Musa paradisiaca flower, Polyscias scutellaria leaf, Coffea liberica Seed, Amaranthus spinosus herbs, Acorus calamus rhizome, Spondias mombin stem bark, Phyllanthus niruri herbs, Eleutherine americana tuber, and Syzygii cumini leaf.
Before the anti-Mycobacterium tuberculosis testing, the extraction process was first carried out. The extraction method used was maceration with $70 \%$ ethanol. It is one type of extraction method with a system without heating so that it is an extraction technique that can be used for compounds that are not heating resistant, tools used are simple, operational costs are relatively low and minimize the use of solvents. The extracted rendamen obtained ranged from $1.3 \%$ to $13.87 \%$ (Table 1 ).

Table 1. Data on extracting simplisia (unprocessed natural ingredients) by maceration method using $70 \%$ ethanol.

\begin{tabular}{|c|c|c|}
\hline No & Simplisia of Plant & Yield (\%) \\
\hline \hline 1 & Collocasia esculanta & 8,184 \\
\hline 2 & Musa paradisiaca & 1,3 \\
\hline 3 & Polyscias scutellaria & 13,87 \\
\hline 4 & Coffea liberica) & 9,33 \\
\hline 5 & Amaranthus spinosus & 2,15 \\
\hline 6 & Acorus calamus & 5,87 \\
\hline 7 & Spondias mombin & 1,82 \\
\hline 8 & Phyllanthus niruri & 3,26 \\
\hline 9 & Eleutherine americana & 5,355 \\
\hline 10 & Syzygii cumini & 14 \\
\hline
\end{tabular}

The extracts obtained is stable enough towards light and temperature so the ten extracts obtained were then screened for their activity against $M$. tuberculosis to determine which extract was the most active in inhibiting the growth of $M$. tuberculosis strain H37RV and MDR. From the results of screening obtained, ethanol extract from Acorus calamus and Collocasia esculenta at concentrations of $10000 \mu \mathrm{g} / \mathrm{ml}$ can inhibit M. tuberculosis growth (Table 2). The initial screening method used MODS (Microscopic-observed drug susceptibility) because this method is faster in detecting anti- $M$. tuberculosis activity based on the principle that $M$. tuberculosis grows faster in liquid media with the characteristics of tangles and cording, namely forming a cord factor that can be observed under microscopes [11]. Media MODS generally consists of Middlebrook 7H9 media, OADC enrichment, and antibiotic PANTA. Middlebrook $7 \mathrm{H} 9$ contains many organic acids that support the growth of bacteria and citric acid which act as buffers. OADC enrichment contains oleic acid which is a source of free fatty acids, bovine albumin functions to bind free fatty acids to avoid toxic to bacteria and closerosa as an energy source.

MODS culture was incubated at $37^{\circ} \mathrm{C}$ and observed with an inverted light microscope at $40 \mathrm{X}$ magnification. Positive results are characterized by the growth of $M$. tuberculosis in the cord formwhile the negative results are indicated by the absence of growth of M.tuberculosis [10].

Several studies have shown that Talas tuber can be used as an ulcer drug in TB to prevent bleeding. In another study, it was also mentioned that talas contains alkaloids, alkylre- 
Table 2. Anti M. tuberculosis Activity Test Results Ethanol extract with MODS method at a concentration of $10000 \mu \mathrm{g} / \mathrm{ml}$.

\begin{tabular}{|c|c|c|}
\hline Ethanol Extract of & \multicolumn{2}{|c|}{ M. tuberculosis } \\
\hline \hline Sample & MDR & H37RV \\
\hline Collocasia esculanta & - & - \\
\hline Musa paradisiaca & + & + \\
\hline Polyscias scutellaria & + & + \\
\hline Coffea liberica $)$ & + & + \\
\hline Amaranthus spinosus & + & + \\
\hline Acorus calamus & - & + \\
\hline Spondias mombin & + & + \\
\hline Phyllanthus niruri & + & + \\
\hline Eleutherine americana & + & + \\
\hline Syzygii cumini & + & \\
\hline $\begin{array}{l}\text { Note: } \\
\text { (+): presence of growth } \\
(-) \text { no presence of growth }\end{array}$ & & \\
\hline
\end{tabular}

sorcinols, glycosides, phenolics, saponins, sterols, essential oils, resins, lots of sugar and organic acids. In the study of Nakade (2013) which observed the antibacterial effects of Talas, it was mentioned that Talas contains alkaloids, carbohydrates, phenols, tannins, flavonoids, saponins, steroids, quinones, cellulose, terpenoids and glycosides and taro has a good antibacterial effect against infections caused by microorganisms, both gram-positive and negative [12]. Another study conducted by Chakraborty, et al. (2015) of methanol extract from leaves and tubers of $C$. esculenta plants had antimicrobial activity at a concentration of $100 \mathrm{mg} / \mathrm{ml}$ and based on phytochemical analysis showed that Talas tubers contained alkaloids, carbohydrates, tannins and terpenes [13]. Agyare et al. (2016) also examined the broad-spectrum antimicrobial activity of $C$. esculenta leaves with MIC values from 12.5 to $50 \mathrm{mg} / \mathrm{mL}$ [14]. Kariango plants, especially the roots, have activities to inhibit $M$. tuberculosis growth. In addition, Kariango plants, especially the rhizome, have antifungal activity with $2-4 \mathrm{mg} / \mathrm{ml}$ MIC while the antibacterial $\mathrm{MIC}$ is $16-24 \mathrm{mg} / \mathrm{ml}$ [15].

The Talas extract was then isolated for its anti-M. tuberculosis compound based on bioassay guided fractionation. In this study, Isolation of active compound from Talas was done because It activity is better than Kariango. Initial fractionation with Vacuum Liquid Chromatography using the mobile phase of ethyl acetate: ethanol with a concentration gradient obtained 12 fractions and then viewed on the TLC plate (Fig. 1). The obtained fraction was then collected and evaporated until complete evaporation, then each fraction was dissolved using methanol solvents and then bottled on thin-layer chromatography Check the profile with the stationary phase of silica gel 60 F254 and ethyl acetate: ethanol (1: 3$)$. The fraction with the same or similar TLC profile is combined, so that the two combined fractions are F1 and FII. Each combined fraction was tested for its activity against M. tuberculosis H37RV and MDR bacteria using the MODS and LJ methods. Fraction II has the greatest anti-M. tu- berculosis activity, then the purification process is carried out.

Fractionation was carried out on Talas ethanol extract using vacuum liquid chromatography with the consideration that this method was classified as fast in separating an extract into different fractions. The selection of the mobile phase used in vacuum liquid chromatography is based on the orientation results with thin layer chromatography. The concentration gradient system used is ethyl acetate, ethanol and methanol with a volume of $100 \mathrm{ml}$ each.

Fraction II was then purified using preparative TLC with a mobile phase of ethyl acetate : ethanol $(1: 3 \mathrm{v} / \mathrm{v})$. In this research, three isolates were derived as they were identified based on spectroscopy data.

The detection result with visible ultraviolet detector using Scanner towards the active antibacterial isolate showed that isolate 1 and 3 show the presence of the peak of maximal absorption at the wavelength of 240,0 . The isolated compound was in yellowish color. While isolate 2 indicates the presence of the peak of maximal absorption in the wavelength of 236,0 .

To identify the functional groups in the isolated compound, infrared spectrophotometer using Shimadzu FTIR is needed to analyze Antibacterial isolate having several functional groups that showed an absorbed band at a wavelength of $3446 \mathrm{~cm}-1$ with high intensity in the presence of $\mathrm{OH}$ groups. Besides, the presence of the bands on wavelength of $2960 \mathrm{~cm}^{-1}$ showed the presence of an aliphatic $\mathrm{CH}$ group. Absorption in the wavelength of $1382,96 \mathrm{~cm}^{-1}$ characterized the $\mathrm{C}-\mathrm{O}$ extend vibration and $\mathrm{O}-\mathrm{H}$ bend [16]. The isolated compound was predicted to be of carboxylic group.

Determination of MIC value of the active extract was done by making concentration variation of $20 \mathrm{mg} / \mathrm{mL}, 25$ $\mathrm{mg} / \mathrm{mL}, 30 \mathrm{mg} / \mathrm{mL}, 35 \mathrm{mg} / \mathrm{mL}$ and $40 \mathrm{mg} / \mathrm{mL}$ using MODS method with broth media. The result showed that the MIC value for both of Kariango (Acorus calamus) rhizome ethanolic extract and Talas (Collocasia esculenta) tuber ethanolic extract was $40 \mathrm{mg} / \mathrm{mL}$. Compared to the MIC value of isoniazid that was of $0,1 \mu \mathrm{g} / \mathrm{mL}$, it was surely far different because the MIC value that has determined was from the crude extract that still contained many kinds of compounds. It was not in a pure compound form.

\section{CONCLUSION}

Based on the result and discussion of this research, it can be concluded that Talas (Collocasia esculenta) tuber and Kariango (Acorus calamus) rhizome ethanolic extract have antituberculosis activity with MIC (Minimum Inhibitory Concentration) value in inhibiting the H37RV M. tuberculosis and MDR-M. tuberculosis was of $40 \mathrm{mg} / \mathrm{mL}$. Based on FTIR data, the active compound of Talas (Collocasia esculenta) tuber contained $\mathrm{OH}$ groups, $\mathrm{C}-\mathrm{O}$ groups, aliphatic $\mathrm{CH}$ groups.

\section{LIST OF ABREVIATION}

MDR-TB = Multi-Drug Resistant Tuberculosis 


$\begin{array}{lll}\text { MODS method } & =\begin{array}{l}\text { Microscopic Observation Drug } \\ \text { Susceptibility method } \\ \text { LJ media method }\end{array} & \begin{array}{l}\text { Lowenstein Jensen media } \\ \text { method }\end{array} \\ \text { FTIR spectroscopy } & =\begin{array}{l}\text { Fourier-transform infrared spec- } \\ \text { troscopy }\end{array} \\ \text { TLC plate } & = & \begin{array}{l}\text { Thin Chromatography Layer } \\ \text { plate }\end{array} \\ \text { OADC } & =\begin{array}{l}\text { Oleic Albumin Dextrose Cata- } \\ \text { lase }\end{array} \\ \text { Anti-TB } & =\text { Anti-tuberculosis }\end{array}$

\section{ETHICS APPROVAL AND CONSENT TO PARTICIPATE}

Not applicable.

\section{HUMAN AND ANIMAL RIGHTS}

No Animals/Humans were used for studies that are base of this research.

\section{CONSENT FOR PUBLICATION}

Not applicable.

\section{AVAILABILITY OF DATA AND MATERIALS}

Not applicable.

\section{FUNDING}

None.

\section{CONFLICT OF INTEREST}

The authors declare no conflict of interest, financial or otherwise.

\section{ACKNOWLEDGEMENTS}

This research was funded by RISTOJA - Balai Besar Penelitian dan Pengembangan Tanaman Obat dan Obat Tradisional - Ministry of Health, Indonesia.

\section{REFERENCES}

[1] Global Tuberculosis Report 2014., 2014,

[2] Silva, P.A; Boffo, M.M.S; Mattos, I.G; Silva, A.B.S; Palomino, J.C; Martin, A.; Takiff, H.E. Comparison of redox and D29 phage methods for detection of isoniazid and rifampicin resistance in Mycobacterium tuberculosis. Clin. Microbiol. Infect., 2006, 12(3), 293-296.

[3] National Guide in Tackling Tuberculosis., (2nd ed. ) 2006, , 3-4.

[4] WHO: Global Tuberculosis Report 2012., 2012,

[5] Rostinawati, T. Antibacterial activity of ethanolic and water extract of Rosella (Hibiscus sabdarifa L.) calyx towards Mycobacterium tuberculosis strain Labkes-026 (Multi-drug Resistant) and Mycobacterium tuberculosis strain H37Rv via in vitro. Padjajaran university, pharmacy faculty.,

[6] Ramos, D.F.; Leitão, G.G.; Costa, F.N.; Abreu, L.; Villarreal, J.V.; Leitão, S.G.; Fernández, S.L.S.; Silva, P.E.A. Investigation of the antimycobacterial activity of 36 plant extracts from the brazilian Atlantic Forest. Braz. J. Pharm. Sci., 2008, 44(4), ••.

[7] Gemechu, A.; Giday, M.; Worku, A.; Ameni, G. In vitro antimycobacterial activity of selected medicinal plants against Mycobacterium tuberculosis and Mycobacterium bovis strains. BMC Complement. Altern. Med., 2013, 13, 291. [http://dx.doi.org/10.1186/1472-6882-13-291] [PMID: 24168665]

[8] Research report of Ristoja (Riset Tanaman Obat dan Jamu) 2012, South Sulawesi Province., 2012.

[9] Research report of Ristoja (Riset Tanaman Obat dan Jamu) 2015, South Sulawesi Province., 2015.

[10] Anita, T. S.S., Ladju, R.B., Massi, N., Evaluation of the Microscopic Observation Drug Susceptibility Assay Drug Concentration for Detection of Multidrug-Resistant Tuberculosis. International Journal of Medical Health. Pharmaceutical and Biomedical Engineering., 2014, 8(5), 257-260.

[11] Caviedes, L.; Moore, D.A.J. Introducing MODS: a low-cost, lowtech tool for high-performance detection of tuberculosis and multidrug resistant tuberculosis. Indian J. Med. Microbiol., 2007, 25(2), 87-88 [http://dx.doi.org/10.4103/0255-0857.32711] [PMID: 17582175]

[12] Nakade, B.D.; Kadam, M.S.; Patil, K.N.; Mane, V.S. Phytochemical screening and antibacterial activity of western region wild leaf Colocasia esculenta. Int. Res. J. Biol. Sci., 2013, 2(10), 18-21.

[13] Chakraborty, P.; Deb, P.; Chakraborty, S.; Chatterjee, B.; Abraham, J. Cytotoxity and antimicrobial activity af Colocasia esculenta. J. Chem. Pharm. Res., 2015, 7(12), 627-635.

[14] Agyare, C.; Boakye, D.Y.; Apenteng, J.A.; Dapaah, S.O.; Appiah, T.; Adow, A. Antimicrobial and Anti-Inflammatory Prooerties of Anchomanes difformis (BI.).Engl, and Colocasia esculenta (L.) Schott. Biochem. Pharmacol. (Los Angel.), 2016, 5, 1.

[15] Devi, A.; Ganjewala, D. Antimicrobial activity of Acorus calamus (L.) rhizome and leaf extract. Acta Biol. Szeged., 2009, 53(1), 4549. 